\title{
Sympathetic activity is reduced by nCPAP in hypertensive obstructive sleep apnoea patients
}

\author{
J. Heitmann*, K. Ehlenz*, T. Penzel*, H.F. Becker*, L. Grote*,\#, K.H. Voigt ${ }^{\Uparrow}$, J. Hermann Peter*, \\ C. Vogelmeier*
}

Sympathetic activity is reduced by $n C P A P$ in hypertensive obstructive sleep apnoea patients. J. Heitmann, K. Ehlenz, T. Penzel, H.F. Becker, L. Grote, K.H. Voigt, J. Hermann Peter, C. Vogelmeier. C) ERS Journals Ltd 2004.

ABSTRACT: There is increasing evidence that nasal continuous positive airway pressure (nCPAP) lowers blood pressure in obstructive sleep apnoea (OSA) patients, not only during sleep but also in the daytime. However, both the mechanisms of blood pressure reduction and the considerable differences in the magnitude of the effect in the studies presented to date are not fully understood.

Therefore, the authors prospectively studied the effect of nCPAP on noradrenaline plasma levels (NApl), blood pressure and heart rate (HR) in 10 normotensive and eight hypertensive OSA patients before and after 41.6 \pm 16.9 days of nCPAP therapy. Polysomnography and invasive blood pressure were continuously monitored over $24 \mathrm{~h}$ in the supine position before and with nCPAP. NApl were analysed every 15 min.

In hypertensives, nCPAP reduced NApl by $36 \pm 25 \%$, lowered mean arterial blood pressure substantially (night-time: $-\mathbf{8 . 8 9} \pm 14.09 \mathrm{mmHg}$; daytime: $-7.94 \pm 10.47 \mathrm{mmHg}$ ) and decreased $H R$ by $6.6 \pm 5.4$ beats $\cdot \mathrm{min}^{-1}$, whereas in normotensives there were only minor changes.

The decrease in heart rate was associated with a decrease in mean arterial blood pressure and noradrenaline plasma levels, suggesting a causal effect of nasal continuous positive airway pressure therapy. This nasal continuous positive airway pressure effect occurs mainly in hypertensive obstructive sleep apnoea patients, whereas the effect is small in normotensives. This may explain, at least in part, some of the discrepant results in previous treatment studies.

Eur Respir J 2004; 23: 255-262.
*Sleep Laboratory, Division of Pulmonary Diseases, Dept of Internal Medicine, and Dept of Physiology, Marburg University, Germany. \#Dept of Pulmonary Medicine, Sahlgrenska University Hospital, Gothenburg, Sweden.

Correspondence: J. Heitmann, Klinik für Innere Medizin, SP Pneumologie, Schlafmedizinisches Labor, Klinikum der Philipps-Universität Marburg, Baldingerstrasse D-35033, Marburg, Germany.

Fax: 496421284958

E-mail: heitmanj@med.uni-marburg.de

Keywords: Continuous positive airways pressure treatment

hypertension

sleep apnoea

sympathetic activity

Received: February 122003

Accepted after revision: September 222003

This study was supported by a scientific grant from the Deutsche Forschungs gemeinschaft (Eh 149/1-1).
Obstructive sleep apnoea (OSA) is characterised by repetitive reduction or cessation of airflow due to partial or complete upper airway obstruction [1]. It results in repeated night-time hypoxaemia, sleep fragmentation and excessive daytime sleepiness. This disorder, which is prevalent in the adult population [2], has been associated with an increased incidence in cardiovascular morbidity, particularly in arterial hypertension [3]. OSA is over-represented in the male population [2]. Sleep fragmentation due to repeated arousal [4] and apnoea-related episodic hypoxaemia [5] have been suggested as possible mechanisms of the increased sympathetic activity that is present in OSA. There is growing evidence that this increased sympathetic activity may play a major pathogenic role in the development of cardiovascular complications [6-9]. In OSA, plasma levels of noradrenaline (NApl), which correlate with sympathetic activity [10], have been found to be elevated both during sleep and wakefulness $[11,12]$.

Nasal continuous positive airway pressure (nCPAP), currently the treatment of choice in moderate-to-severe OSA [13], prevents upper airway obstruction and restores daytime symptoms [14, 15]. A reduction in sympathetic activity in OSA patients on nCPAP has been shown in several studies [16-18]. Data concerning the effect of nCPAP on blood pressure are conflicting. Recently published controlled studies on the effects of nCPAP on arterial blood pressure demonstrated a small reduction $(-1.4$ and $-2.5 \mathrm{mmHg}$, respectively) in blood pressure with nCPAP therapy [19, 20], whereas others didn't find a blood pressure drop with nCPAP [21] or only during the night [22]. However, post-hoc analysis in one study [19] revealed that the subgroups with severe hypertension and severe OSA may have more profound reductions in blood pressure. Conversely, a recently published controlled study from the current authors' group demonstrated $\sim 10 \mathrm{mmHg}$ decrease in both day- and night-time blood pressure in patients with moderate-to-severe OSA treated with nCPAP for 9 weeks on average [23]. Twenty-one of the 32 patients studied were hypertensive.

There are a number of methodological problems in previous studies, which may explain the conflicting results from these trials: 1) exclusively or mainly normotensive patients were included in the studies that did not show an effect of nCPAP on blood pressure; 2) discontinuous blood pressure measurement may underestimate blood pressure changes; and 3) activity levels were not controlled. Therefore, the present authors conducted a study evaluating the effect of nCPAP on arterial blood pressure, heart rate (HR) and sympathetic activity. Normo- and hypertensive OSA patients 
were investigated using invasive continuous blood pressure monitoring during a 24-h constant routine with defined activity and resting levels.

\section{Methods}

\section{Subjects}

Consecutive patients were recruited from the out-patient department of the Marburg Sleep Laboratory (Marburg, Germany). The indication for cardiorespiratory polysomnography due to suspected sleep apnoea was based on clinical symptoms, ambulatory nocturnal recording of HR, snoring, oxygen saturation and body position using a validated fourchannel ambulatory device (MESAM IV ${ }^{\mathbb{R}}$; Madaus Medizintechnik, Munich, Germany). Blood pressure and HR profiles were obtained over $24 \mathrm{~h}$ using the SpaceLabs $90207^{\mathbb{R}}$ (SpaceLabs Medical, Inc., Redmond, WA, USA), which provides oscillometric blood pressure measurements. Measurement intervals were $20 \mathrm{~min}$ during the day and 30 min during the night.

Inclusion criteria included: age 20-65 yrs, apnoea-hypopnoea index $(\mathrm{AHI})>20 \cdot \mathrm{h}^{-1}$. Exclusion criteria included: systolic blood pressure $>220 \mathrm{mmHg}$ or diastolic blood pressure $>110 \mathrm{mmHg}$; myocardial infarction; stroke; heart failure; neurological disease; or a history of alcohol or drug abuse. Concomitant antihypertensive medication was discontinued at least 3 weeks before the study began. A patient was assigned to the hypertensive group when daytime average blood pressure in the ambulatory blood pressure measurement was $\geqslant 135 / 85 \mathrm{mmHg}$ [24].

Demographic characteristics, AHI (at baseline and with nCPAP therapy), data of the ambulatory blood pressure measurements, and the duration of nCPAP use as well as nCPAP pressure of the normotensives and the hypertensives are shown in table 1.

\section{Study protocol}

Patients eligible for the study were hospitalised for a period of 5 days. Following baseline recordings (see below), all patients were put on nCPAP treatment. The follow-up measurements were carried out after a minimum of 4 weeks

Table 1.-Characteristics of the normotensive and hypertensive obstructive sleep apnoea patients

\begin{tabular}{lcc}
\hline & Normotension & Hypertension \\
\hline Subjects n & 8 & 10 \\
Age yrs & $52.63 \pm 10.14$ & $47.90 \pm 10.57$ \\
Height cm & $178.13 \pm 7.80$ & $177.50 \pm 5.21$ \\
Weight kg & $86.00 \pm 16.11$ & $100.30 \pm 7.73^{*}$ \\
BMI kg·m & & \\
$\quad$ Baseline & & \\
nCPAP & $27.00 \pm 3.44$ & $31.84 \pm 2.16^{*}$ \\
SBP mmHg & $27.10 \pm 3.73$ & $31.60 \pm 2.24^{*}$ \\
DBP mmHg & $123.50 \pm 10.56$ & $147.5 \pm 9.81^{*}$ \\
AHI ${ }^{-1}$ Baseline & $75.88 \pm 11.56$ & $92.1 \pm 7.91^{*}$ \\
Mean $S_{\mathrm{a}, \mathrm{O}_{2}}$ & $42.75 \pm 19.95$ & $70.25 \pm 28.94^{*}$ \\
Mean use of nCPAP·day ${ }^{-1} \mathrm{~h}$ & $93.25 \pm 1.91$ & $92.00 \pm 4.35$ \\
Mean duration of nCPAP & $5.84 \pm 0.75$ & $5.67 \pm 0.68$ \\
$\quad$ use days & $46.53 \pm 20.13$ & $46.03 \pm 14.47$ \\
\end{tabular}

Data are presented as mean \pm SD. BMI: body mass index; nCPAP: nasal continuous positive airway pressure; AHI: apnoea/hypopnoea index; SBP/DBP: systolic/diastolic blood pressure (mean of daytime values in the ambulatory blood pressure monitoring). ${ }^{*}: \mathrm{p}<0.05$ between the two groups. of home use of nCPAP therapy. To encourage the patients to use the nCPAP therapy regularly and to increase compliance, weekly telephone contacts and a follow-up in the out-patient department after 2 weeks were performed. Compliance with nCPAP treatment was measured with a run-time counter, which ran when the machine was switched on. A minimum of $5 \mathrm{~h} \cdot$ night $^{-1}$ was set as the minimum threshold for compliance.

This study was approved by the Ethics Committee of Marburg University. Patients gave written informed consent before the start of the study.

\section{Data collection}

Subjects underwent baseline and treatment measurement periods in the supine position for $26 \mathrm{~h}(08: 00-22: 00 \mathrm{~h}$, meals were taken in the sitting position), with continuous radial arterial blood pressure monitoring and according to the following standardised procedure: $12 \mathrm{~h}$ in advance of the 26-h period, the cannulation of the radial artery was performed on the nondominant arm. The night (with the complete measuring equipment) prior to the 26 -h period served for adaptation. A venous line was inserted antecubital in the early morning after the first night and catecholamine sampling started $2 \mathrm{~h}$ after insertion, with $4 \mathrm{~mL}$ blood being collected every $15 \mathrm{~min}$ (a total of $400 \mathrm{~mL} \cdot \mathrm{day}^{-1}$, the dead space volume of the catheter line was excluded from the analysis) through a long tube from an adjacent room, in order not to disturb sleep. To maintain blood flow, the venous line was rinsed with RingerHeparin $\left(500 \mathrm{E} \cdot \mathrm{L}^{-1}, 20 \mathrm{~mL} \cdot \mathrm{h}^{-1}\right.$ resulting in $\left.480 \mathrm{~mL} \cdot \mathrm{day}^{-1}\right)$. The blood samples were collected in prechilled ethylenediamine tetraacetic acid-containing tubes and plasma was separated immediately with cold centrifugation. The plasma tubes were stored at $-70^{\circ} \mathrm{C}$ and analysed after completing all recordings. All patients had their meals (low protein diet) at fixed times (08:00, 12:00 and 18:00 h). Liquid intake and urine excretion (sampled with a urinal) were recorded. Patients were allowed to read and listen to music during the study period. Standard polysomnography was performed from 10:00-10:00 h.

\section{Data analysis}

Standard polysomnography was scored according to the criteria of RECHTSCHAFFEN and KALES [25]. Within the 24-h period, sleep and wakefulness were differentiated. Phases of wakefulness after sleep onset and sleep phases during the day were excluded from analysis.

The AHI (events per hour) was calculated from abnormal breathing events in relation to the total sleep time and classified according to standardised criteria. Oronasal airflow was recorded by the use of a thermistor and respiratory effort by inductive plethysmography (Respitrace $\mathbb{R}$; Studley Data Systems, Oxford, UK). An apnoea was defined as the cessation of airflow for at least $10 \mathrm{~s}$. Hypopnoea was defined as a reduction of airflow by $\geqslant 50 \%$ lasting for $\geqslant 10 \mathrm{~s}$, accompanied by a decrease in arterial oxygen saturation $\left(\mathrm{Sa}, \mathrm{O}_{2}\right)$ of at least $4 \%$ of the preceding stable $\mathrm{Sa}_{2} \mathrm{O}_{2}$.

Blood pressure and electrocardiogram (ECG) were digitised at $100 \mathrm{~Hz}$. HR was derived from the ECG signal using an R-wave detection. Mean values of blood pressure and HR were calculated for 15 -min periods corresponding to the blood sampling. Scoring of polysomnography, and analysis of blood pressure and HR were done by a technician otherwise not involved in the study.

Adrenaline plasma levels (Apl) and NApl were measured by high-performance liquid chromatography with electrochemical detection using the method application of Chromosystems Instruments \& Chemicals GmbH (Munich, Germany). The 
intra-assay coefficient of variation was 5.6 and $6.1 \%$ respectively, the sensitivity was 54.7 and $59.1 \mathrm{pmoL} \cdot \mathrm{L}^{-1}$ respectively.

\section{Statistical analysis}

All values are given as mean \pm SD unless otherwise stated. The main end-point was mean arterial blood pressure (MAP), defined as the arithmetic mean over the 24 -h period at baseline and with nCPAP treatment. Secondary end-points were HR and the NApl as means over the 24-h period, as well as MAP, HR and NApl during sleep and wakefulness. Statistical analysis of the treatment effects was performed using the Mann-Whitney U-test for nonparametric variables (nonnormal distribution) and the paired t-test for parametric variables (normal distribution). A p-value of $<0.05$ was considered significant.

Hypothesis-generating post-hoc analysis was performed by means of correlation analysis and partial correlation analysis. Multiple testing was performed without adjustment for the significance level. Multivariate regression analysis was used to assess independent associations.

\section{Missing data}

A total of 26 patients were enrolled in the study. Fifteen were hypertensive and 11 normotensive. Eight subjects did not complete the study and were withdrawn from the analysis. The data of 18 patients (10 hypertensives and eight normotensives), in whom the analysis of both blood pressure and catecholamines at baseline and with nCPAP treatment was available over the entire $24-\mathrm{h}$ period, are presented here.

\section{Results}

\section{Blood pressure, heart rate and catecholamines}

There was a substantial decrease in NApl in the hypertensives $\left(1,679 \pm 539\right.$ to $\left.1,081 \pm 489 \mathrm{pmol} \cdot \mathrm{L}^{-1} ; \mathrm{p}=0.001\right)$ but not in the normotensives $\left(1,449 \pm 447\right.$ to $\left.1,385 \pm 524 \mathrm{pmol} \cdot \mathrm{L}^{-1}\right)$. No significant changes in Apl levels, either in the normotensives nor in the hypertensives, occurred (normotensives: 143.1士 28.9 to $126.7 \pm 54.7 \mathrm{pmol} \cdot \mathrm{L}^{-1}$; hypertensives: $137.4 \pm 36.8$ to $\left.137.8 \pm 36.21 \mathrm{pmol} \cdot \mathrm{L}^{-1}\right)$. MAP decreased significantly with nCPAP in the hypertensive group from 103.2 \pm 13.7 to $95.0 \pm 12.3 \mathrm{mmHg}(\mathrm{p}=0.04)$, whereas in the normotensive group there was only a minor decrease in MAP $(89.0 \pm 15.3$ to $87.3 \pm 12.6 \mathrm{mmHg} ; \mathrm{p}=0.7)$. In the hypertensive group, average HR decreased significantly from $76.3 \pm 5.16$ to $69.8 \pm$ 6.0 beats $\cdot \min ^{-1}(p=0.004)$, while no such effect was observed in the normotensive group $\left(68.1 \pm 6.1\right.$ to $67.4 \pm 4.8$ beats $\left.\cdot \mathrm{min}^{-1}\right)$ (fig. 1). The reduction in MAP and HR, as well as in NApl, in the hypertensives was present both during sleep and wakefulness (fig. 2). Individual means of MAP, HR and NApl at baseline and with nCPAP treatment are presented in figure 3 . NApl, MAP and HR during wakefulness and sleep are shown in table 2.

Effects of nasal continuous positive airway pressure on sleep-disordered breathing and sleep

In all 18 patients, good compliance with nCPAP therapy was achieved, the mean duration of nCPAP use being $5.7 \pm 0.68 \mathrm{~h} \cdot$ night $^{-1}$. nCPAP compliance did not differ between the groups. The data on AHI and the sleep stages before and during treatment are shown in table 3. With nCPAP, an
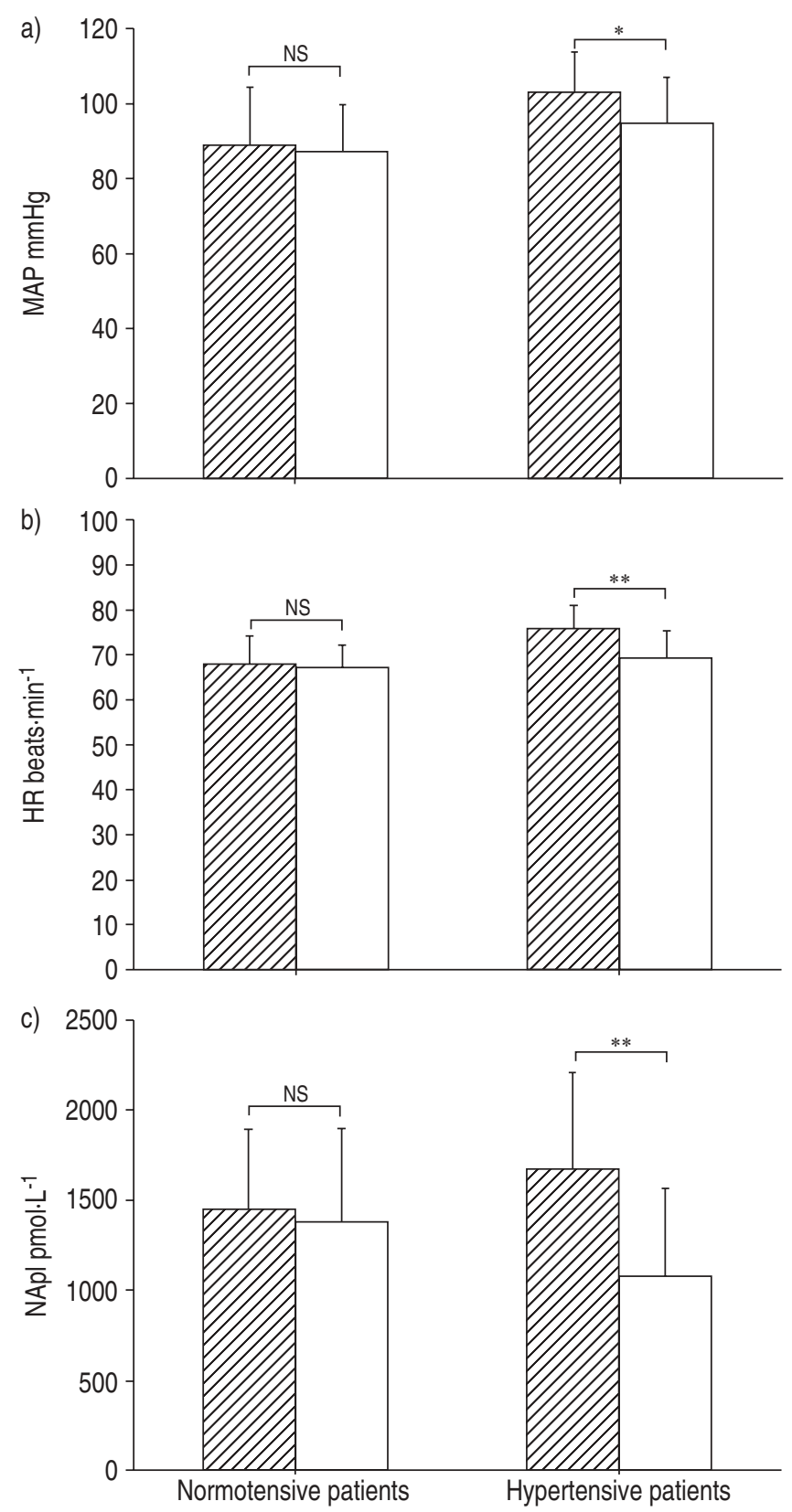

Fig. 1.- Twenty-four-hour mean arterial blood pressure (MAP), heart rate $(\mathrm{HR})$ and noradrenaline plasma levels (NApl) at baseline $(\mathbb{Z})$ and with nasal positive airway pressure treatment $(\square)$ in the normotensive and the hypertensive patients. Data are presented as mean \pm SD. NS: nonsignificant; $*: \mathrm{p} \leqslant 0.05 ; * *: \mathrm{p} \leqslant 0.01$

almost complete removal of sleep-disordered breathing was achieved in all patients. In both groups, sleep efficacy increased with nCPAP. The percentage of slow-wave sleep (SWS) at baseline was higher in the normotensive group, while the increment of SWS under nCPAP was more marked in the hypertensive group. Apart from these findings, there were no other differences between the groups at baseline or with nCPAP therapy.

Interaction of factors associated with the observed change in 24-h blood pressure and heart rate

Whole group analysis $(n=18)$. There was a highly significant correlation of the individual baseline-therapy difference in 

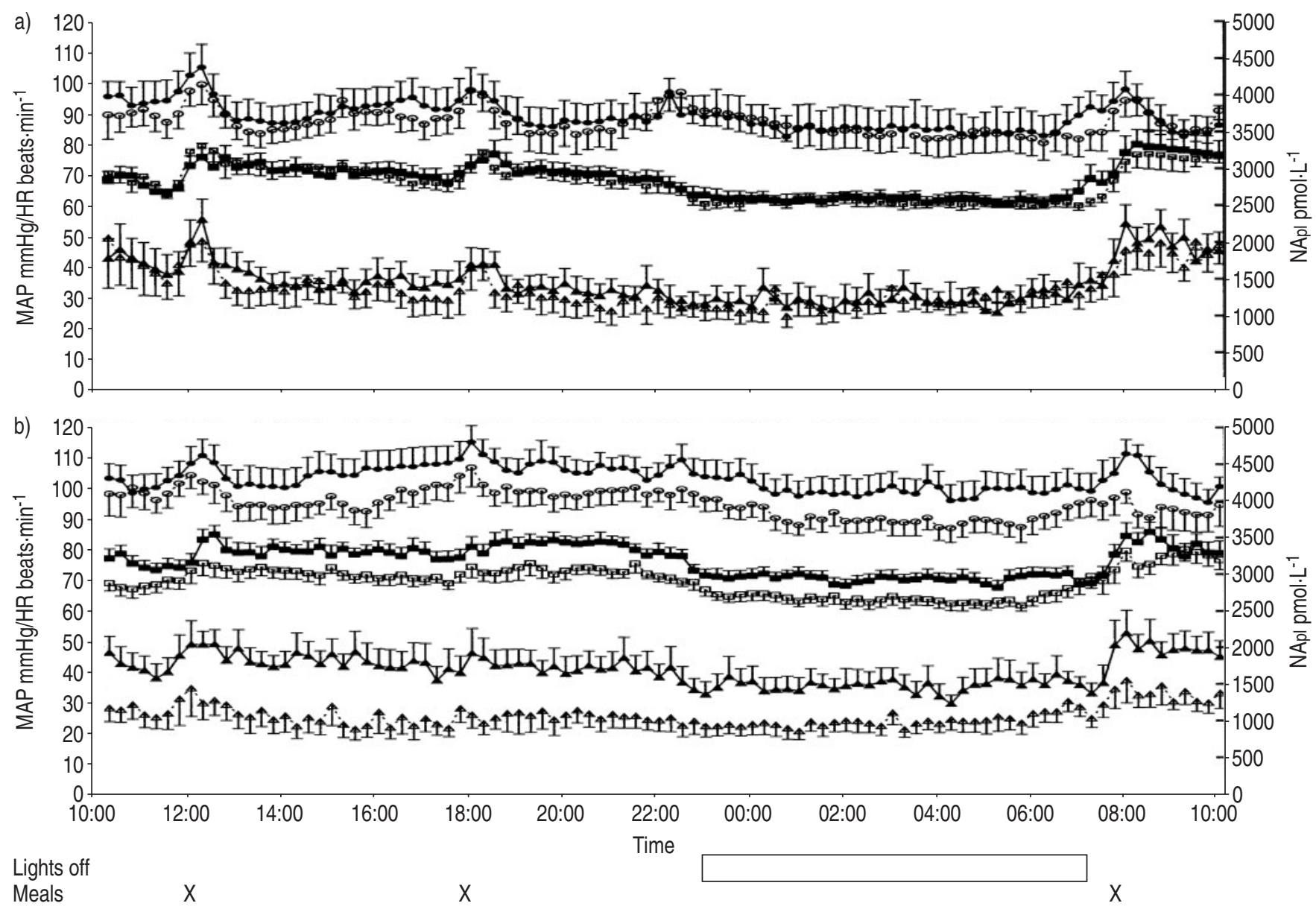

Fig. 2. - Twenty-four-hour profiles of mean arterial blood pressure (MAP; circles), heart rate (HR; squares) and noradrenaline plasma levels (NApl; triangles) in the normotensive (a) and the hypertensive (b) patients at baseline (filled symbols) and with nasal continuous airway pressure treatment (open symbols). Data are presented as mean \pm SEM of all patients over a 15 -min time period.

NApl with the changes in HR ( $\mathrm{r}=0.611, \mathrm{p}=0.007$, fig. 4). Furthermore, the change in HR was strongly associated with the change in systolic, mean and diastolic blood pressure ( $\mathrm{r}=0.65,0.64,0.61, \mathrm{p}<0.005$, respectively). However, the association between the change in catecholamines and other haemodynamic parameters was less obvious and showed only a statistical trend between the changes in NApl and systolic blood pressure $(r=0.40, p=0.10)$.

A multiple regression model was built taking baselinetherapy differences of systolic blood pressure, diastolic blood pressure, mean blood pressure, HR and NApl as dependent, and age, body mass index (BMI) and respiratory disturbance index (RDI) as independent variables. A statistical trend was seen in the correlation between the RDI at baseline and the decrease in NApl ( $r=-0.579)$, the significance of the coefficient in the model was $\mathrm{p}=0.056$. Patients with higher RDI showed a greater decrease in 24-h NApl with nCPAP therapy.

Subgroup analysis (8 normotensives and 10 hypertensives). In the hypertensive OSA patients, the association between the 24-h HR change and the corresponding change in systolic, mean and diastolic blood pressure remained $(\mathrm{r}=0.62,0.73$ and 0.69 , $\mathrm{p}=0.06,0.02$ and 0.03 , respectively, fig. 5). These correlation's changed only slightly when controlled for age and BMI in partial correlation analysis. However, the previously reported associations between the changes in HR and the changes in catecholamines disappeared in the subgroups of normo- and hypertensive patients. Multiple regression analysis was not performed due to the small number of patients in each group.

\section{Discussion}

This study demonstrated that: 1) nCPAP significantly reduced NApl, blood pressure and HR in hypertensive but not in normotensive OSA patients; 2) the reduction in blood pressure during daytime and during sleep was in a similar range; and 3) the reduction of blood pressure was strongly associated with the change in HR.

In the trial presented here there is a clear association between blood pressure reduction and changes in sympathetic activity. The reduction in NApl with nCPAP in the hypertensive patients was observed during the night and also during the day, suggesting that the elimination of OSA with nCPAP has an impact on sympathetic activity beyond the hours of sleep. This effect was not found in the normotensive subjects, which confirms the data of MARRONE et al. [7]. HEDNER et al. [18] also demonstrated a marked reduction of catecholamine excretion in OSA patients with nCPAP both during wakefulness and sleep.

For the first time, this study strongly suggests that the reduction of HR and cardiac output may be an important mechanism for the blood pressure-reducing effect of nCPAP therapy. This is suggested by the strong correlation between the change in HR and the change in blood pressure in the 


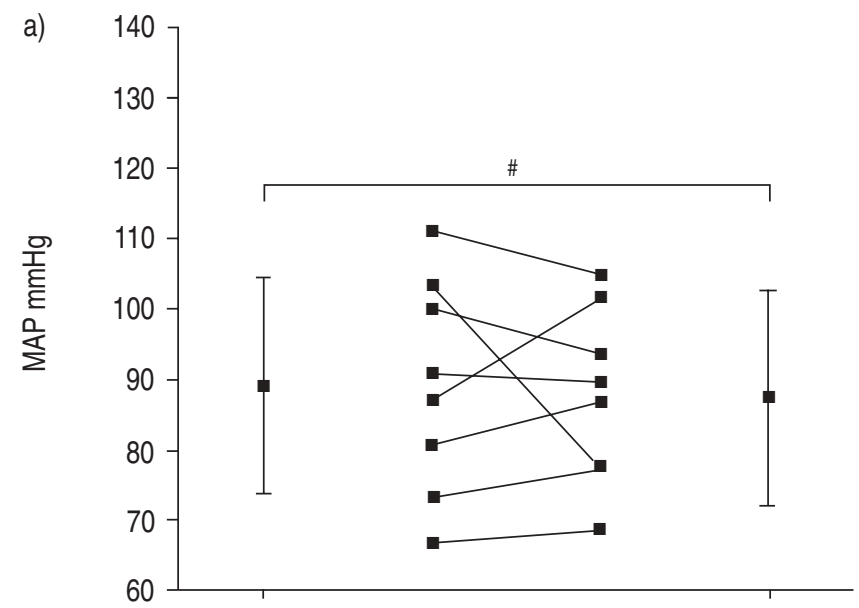

b)
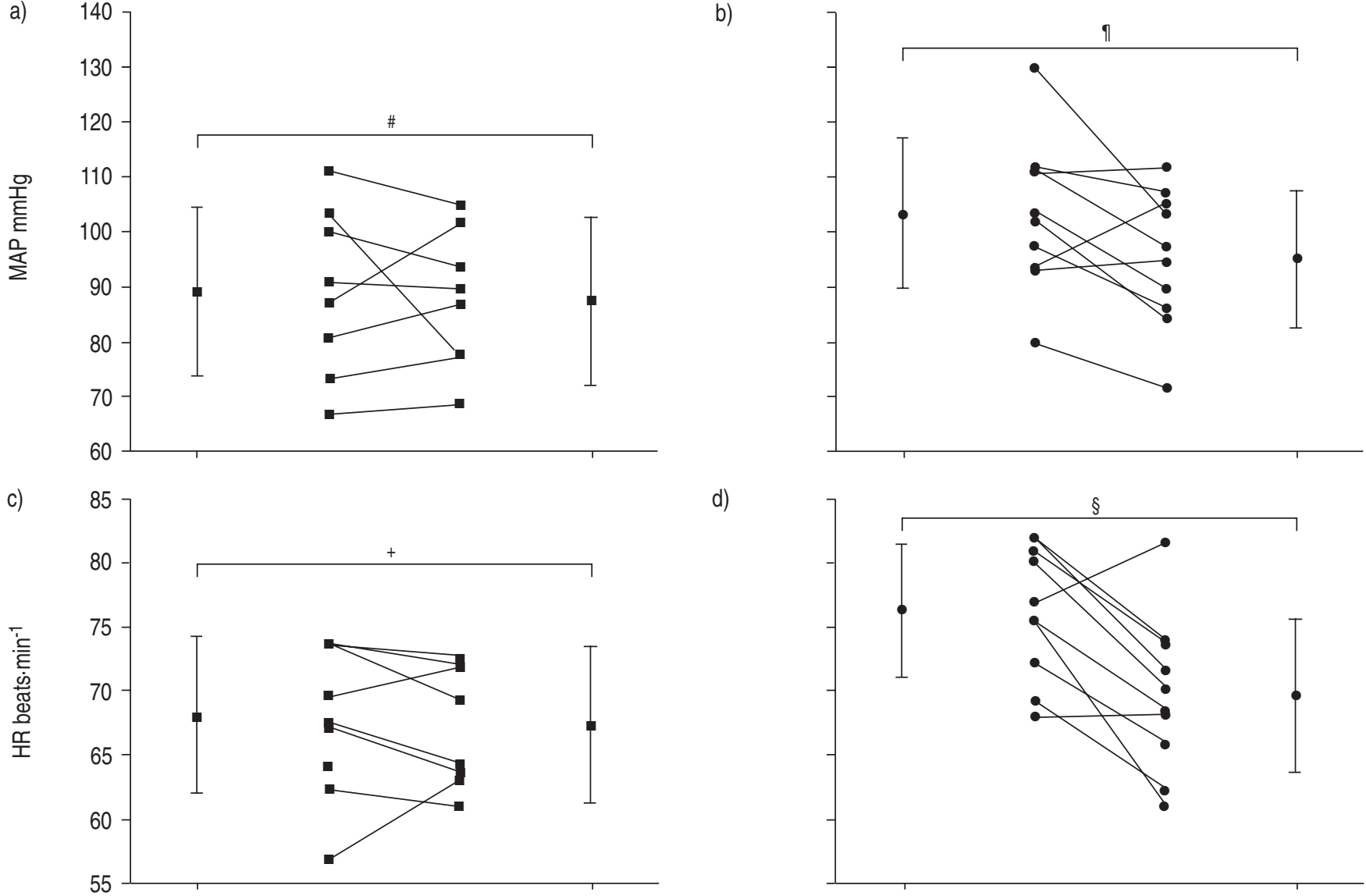

d)
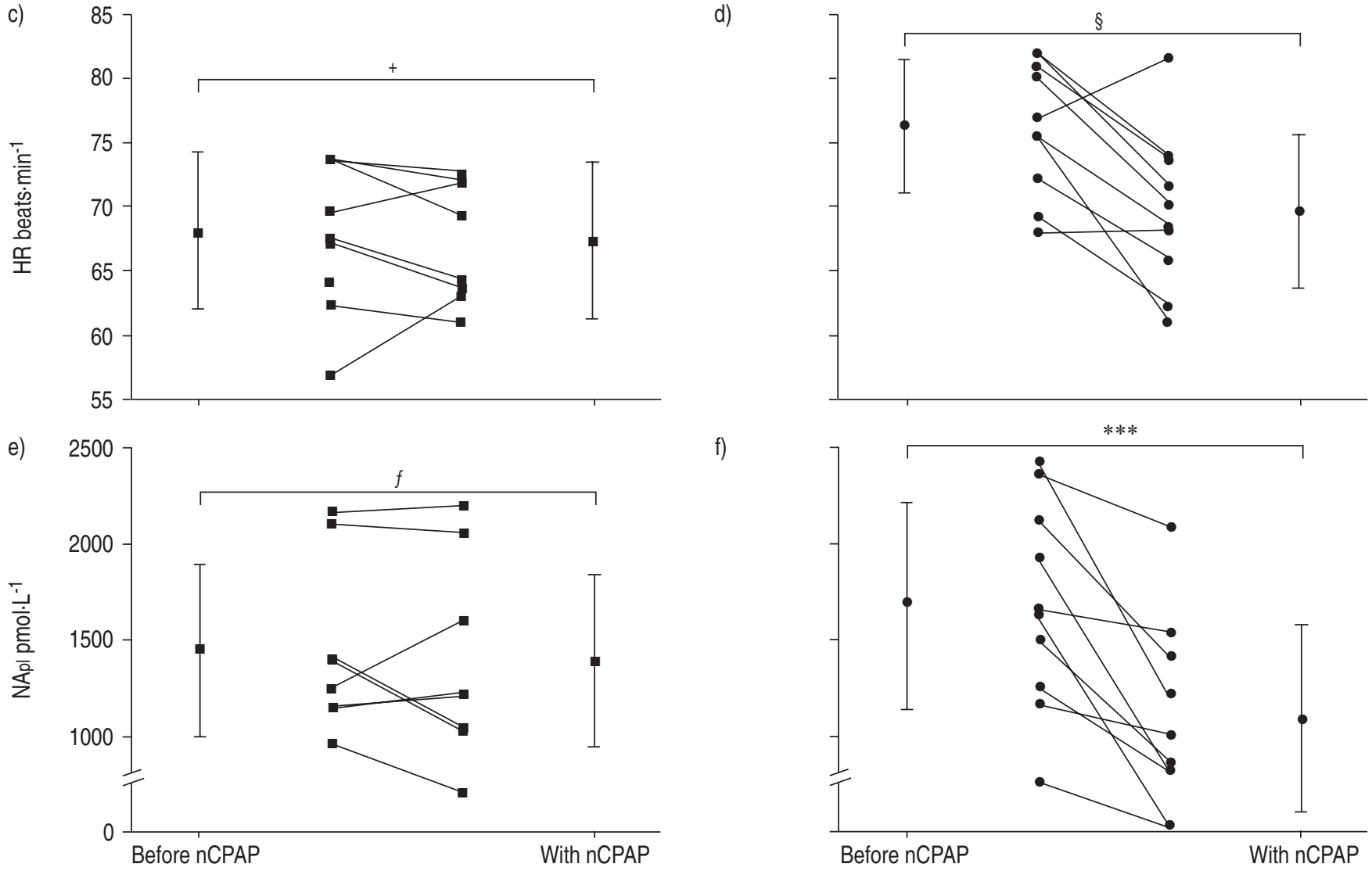

f)

Fig. 3. - Individual 24-h means of mean arterial blood pressure (MAP; a and b), heart rate (HR; c and d) and noradrenaline plasma levels (NApl; $\mathrm{e}$ and $\mathrm{f}$ ) before and with nasal continuous airway pressure (nCPAP) treatment for the normotensive ( $\mathbf{})$ and hypertensive patients $(\bullet)$. Data are presented as mean \pm SD for both groups. ${ }^{\#}: \mathrm{p}=0.7 ;{ }^{\uparrow}: \mathrm{p}=0.04 ;{ }^{+}: \mathrm{p}=0.6 ;{ }^{\S}: \mathrm{p}=0.004 ;{ }^{f}: \mathrm{p}=0.5 ; * * *: \mathrm{p}<0.001$.

whole study group and in the hypertensive subgroup. Furthermore, the current data suggest that this effect may be directly mediated by the reduction of overall sympathetic activity, as indicated by the strong correlation between the changes in circulating NApl and the changes in HR induced by nCPAP. Alternatively, cardiac vagal activity might have been increased as a response to nCPAP therapy (not assessed in this study). Indeed, previous studies reported increased cardiac vagal tone after nCPAP therapy, as assessed by HR variability analysis [26, 27]. There are further mechanisms potentially involved in the observed blood pressure reduction by nCPAP treatment which have not been assessed in this study, e.g. increase in vasodilatory function and nitric oxide content of the endothelium, reduced vasoconstriction due to normalised circulating NA, or change of reactivity of the renin angiotensin system. This lack of information limits the possibility to explain the mechanisms that caused the blood pressure reduction in hypertensives and not in normotensive OSA patients. However, the present study clearly indicates that blood pressure level at baseline and hypertensive state, the severity of OSA, and probably the change in HR with treatment are potential predictors for the blood pressure response to nCPAP therapy.

Most uncontrolled studies have shown a blood pressure 
Table 2. - Mean arterial blood pressure (MAP), heart rate (HR) and noradrenaline plasma levels (NApl) differentiated for wakefulness, sleep and $24 \mathrm{~h}$

\begin{tabular}{|c|c|c|c|c|c|c|c|c|c|}
\hline & \multicolumn{3}{|c|}{ All Patients } & \multicolumn{3}{|c|}{ Normotension } & \multicolumn{3}{|c|}{ Hypertension } \\
\hline & Baseline & nCPAP & Delta \pm SD & Baseline & nCPAP & Delta \pm SD & Baseline & nCPAP & Delta \pm SD \\
\hline \multicolumn{10}{|l|}{ Wakefulness } \\
\hline MAP mmHg & 98.51 & 93.14 & $-5.36 \pm 11.11$ & 90.78 & 88.63 & $-2.15 \pm 11.73$ & 104.69 & 96.75 & $-7.94 \pm 10.47^{*}$ \\
\hline SYS mmHg & 146.83 & 140.82 & $-6.01 \pm 14.10$ & 133.73 & 132.82 & $-0.91 \pm 14.75$ & 157.31 & 147.21 & $-10.09 \pm 12.82 *$ \\
\hline DIA mmHg & 74.75 & 69.57 & $-3.7 \pm 10.82$ & 68.99 & 66.61 & $-2.37 \pm 11.21$ & 79.36 & 71.94 & $-7.42 \pm 10.52$ \\
\hline $\mathrm{HR}$ beats $\cdot \mathrm{min}^{-1}$ & 75.17 & 71.10 & $-4.08 \pm 5.54 * *$ & 70.64 & 70.00 & $-0.66 \pm 3.93$ & 78.80 & 71.96 & $-6.89 \pm 5.2^{* *}$ \\
\hline $\mathrm{NApl} \mathrm{pmol} \cdot \mathrm{mL}^{-1}$ & 281.90 & 213.76 & $-68.13 \pm 79.20^{* *}$ & 261.33 & 245.30 & $-16.03 \pm 45.92$ & 298.34 & 188.53 & $-109.82 \pm 76.57^{* *}$ \\
\hline \multicolumn{10}{|l|}{ Sleep } \\
\hline MAP mmHg & 92.90 & 86.47 & $-6.42 \pm 14.21$ & 85.17 & 83.30 & $-1.86 \pm 13.63$ & 99.10 & 89.01 & $-8.89 \pm 14.09$ \\
\hline SYS mmHg & 138.52 & 127.00 & $-11.52 \pm 17.36^{*}$ & 124.80 & 121.28 & $-3.51 \pm 16.84$ & 149.50 & 131.57 & $-15.88 \pm 16.35^{* *}$ \\
\hline DIA mmHg & 70.09 & 65.67 & $-4.42 \pm 12.43$ & 64.49 & 63.61 & $-0.88 \pm 12.77$ & 74.57 & 67.32 & $-6.32 \pm 12.68$ \\
\hline HR beats $\cdot \min ^{-1}$ & 66.07 & 61.74 & $-4.37 \pm 5.52 * *$ & 61.60 & 60.49 & $-1.11 \pm 2.45$ & 69.66 & 62.74 & $-6.70 \pm 5.76^{* *}$ \\
\hline $\mathrm{NApl} \mathrm{pmol} \cdot \mathrm{mL}^{-1}$ & 227.56 & 181.43 & $-46.12 \pm 69.23 *$ & 202.42 & 201.40 & $-1.03 \pm 54.42$ & 247.66 & 165.46 & $-82.20 \pm 59.14^{* *}$ \\
\hline \multicolumn{10}{|l|}{$24 \mathrm{~h}$} \\
\hline MAP mmHg & 96.91 & 91.57 & $-5.34 \pm 11.61$ & 89.00 & 87.31 & $-1.69 \pm 11.92$ & 103.24 & 94.98 & $-8.26 \pm 11.01 *$ \\
\hline SYS mmHg & 144.47 & 137.53 & $-6.94 \pm 14.22$ & 130.97 & 129.94 & $-1.03 \pm 14.87$ & 155.27 & 143.61 & $-11.66 \pm 11.66^{*}$ \\
\hline DIA $\mathrm{mmHg}$ & 73.42 & 68.66 & $-0.76 \pm 11.17$ & 67.54 & 65.88 & $-1.66 \pm 11.38$ & 78.12 & 70.88 & $-7.25 \pm 10.94$ \\
\hline HR beats $\cdot \min ^{-1}$ & 72.67 & 68.70 & $-3.97 \pm 5.40^{* *}$ & 68.09 & 67.38 & $-0.71 \pm 3.43$ & 76.34 & 69.76 & $-6.58 \pm 5.39^{* *}$ \\
\hline $\mathrm{NApl} \mathrm{pmol} \cdot \mathrm{mL}^{-1}$ & 266.74 & 205.76 & $-60.98 \pm 74.12 * *$ & 245.07 & 234.31 & $-10.76 \pm 42.01$ & 284.08 & 182.91 & $-101.17 \pm 70.49 * *$ \\
\hline
\end{tabular}

Data are presented as mean \pm SD. *: $\mathrm{p}<0.05 ; * *: \mathrm{p}<0.01$.

Table 3. - Parameters of sleep and sleep-disordered breathing at baseline and with nasal continuous airway pressure (nCPAP) therapy

\begin{tabular}{lcccc}
\hline & \multicolumn{2}{c}{ Baseline } & & nCPAP \\
\cline { 2 - 5 } & Normotension & Hypertension & Normotension & Hypertension \\
\cline { 2 - 5 } Subjects n & 8 & 10 & 8 & 10 \\
TST min & $385.61 \pm 68.31$ & $370.00 \pm 42.83$ & $376.46 \pm 53.87$ & $328.85 \pm 47.31$ \\
Sleep stage 1 \% & $16.03 \pm 9.31$ & $14.08 \pm 5.49$ & $56.13 \pm 7.68$ & $10.34 \pm 5.75$ \\
Sleep stage 2\% & $52.66 \pm 14.91$ & $61.22 \pm 11.55$ & $13.68 \pm 3.40$ & $58.21 \pm 6.13$ \\
Sleep stage 3/4 \% & $11.68 \pm 5.87$ & $20.33 \pm 6.37$ & $18.35 \pm 4.58$ & $9.68 \pm 6.27^{\#}$ \\
REM \% & $19.40 \pm 3.96$ & $59.4 \pm 32.14$ & $26.75 \pm 9.77^{\#}$ & $21.59 \pm 6.75$ \\
Waking phases events & $47.5 \pm 27.34$ & $70.25 \pm 28.94$ & $0.30 \pm 0.70^{\#}$ & $30.30 \pm 12.12^{\#}$ \\
AHI events' ${ }^{-1}$ & $42.75 \pm 19.95$ & & $0.41 \pm 1.00^{\#}$ \\
\hline
\end{tabular}

Data are presented as mean \pm SD. ${ }^{\#}$ : significant differences between baseline and nCPAP. TST: total sleep time; REM: rapid eye movement; AHI: apnoea-hypopnoea index.

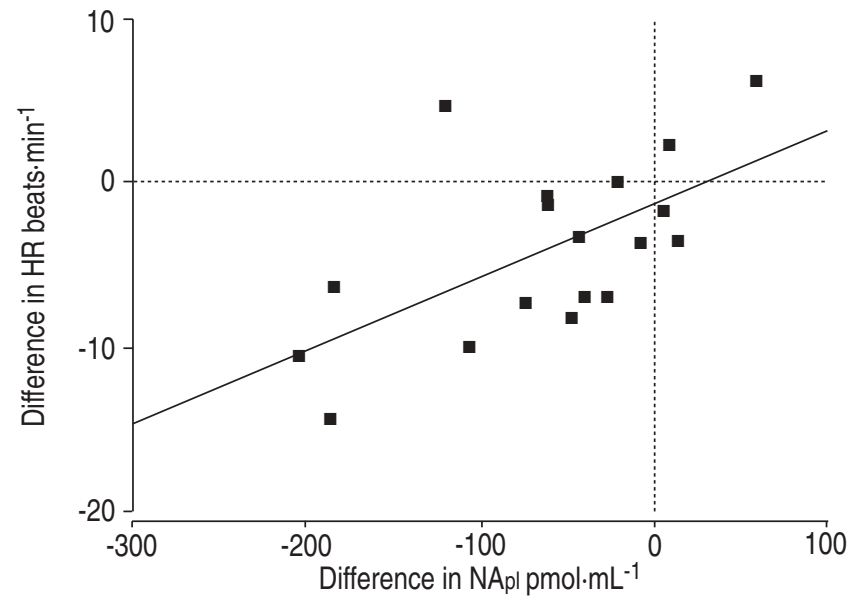

Fig. 4. - There was a significant correlation between the change in mean 24-h noradrenaline plasma levels (NApl) after treatment with nasal continuous airway pressure and the change in mean 24 -h heart rate $(\mathrm{HR})(\mathrm{r}=0.611, \mathrm{p}=0.007, \mathrm{n}=18$ patients $)$.

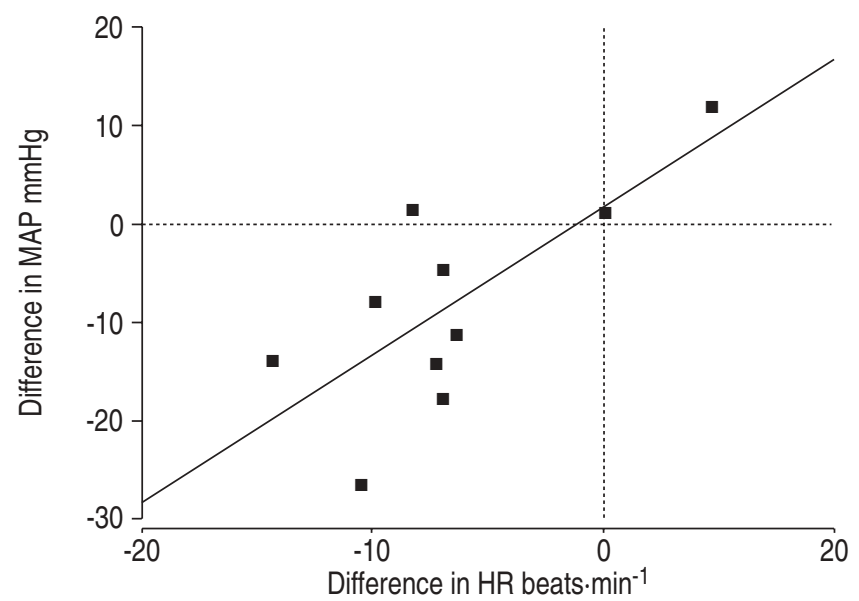

Fig. 5. - In the subgroup of hypertensive patients the change in 24-h mean arterial blood pressure (MAP) after treatment with nasal continuous airway pressure correlated significantly with the change in mean 24-h heart rate $(\mathrm{HR})(\mathrm{r}=0.73, \mathrm{p}=0.02, \mathrm{n}=10$ patients $)$. 
decrease with nCPAP [17, 28]. In a few controlled studies there was either no effect $[21,22]$ or a small decrease in daytime MAP by $1.4-2.5 \mathrm{mmHg}[19,20]$. In the normotensive patients in the current study, the decrease in blood pressure had a similar magnitude $(-1.7 \mathrm{mmHg})$. However, the decrease in MAP in the hypertensive patients was much more pronounced $(-8.3 \mathrm{mmHg})$, similar to the data of BECKER et al. [23]. The discrepant results may be caused by the splitting between hypertensive and normotensive patients, the controlled conditions (activity level, food intake, alcohol consumption, etc.), the lack of confounding antihypertensive medication, and the invasive blood pressure measurement. These factors have not been considered in previous studies.

An unexpected finding in the present study was the extent of the decrease in NApl in the hypertensives with nCPAP therapy; it reached levels below that of the normotensives. This finding remains unexplained. The studies of JENNUM et al. [16] and MinemurA et al. [17], which showed similar results, are not comparable because they did not differentiate between hypertensive and normotensive OSA patients. In the current study, there were no significant changes in adrenaline in the normotensive or in the hypertensive patients. This result confirms previous studies [17, 29].

The strengths of this study were continuous intra-arterial blood pressure recording and the experimental protocol controlling for external conditions and vigilance. Continuous invasive blood pressure measurement was used because of its accuracy and absence of additional sleep disturbances, which is a limiting factor in ambulatory blood pressure monitoring [30]. MAP is the true mean of the blood pressure curve and reflects the mechanical load to the vessels. Therefore, this parameter was chosen as primary end-point. Frequent antecubital plasma NA measurements were not done in OSA patients so far. This method can be used as a surrogate for systemic sympathetic activity [10], while other methods such as microneurography or catecholamine spill over are very cumbersome and cannot be used during a 24-h period.

The major limitation of the current study is the lack of a control group. At the time the study was designed (mid 90th) there was no accepted placebo treatment for OSA. However, this restriction clearly does not influence the main findings of the current study: the group difference between normoand hypertensives, the association between blood pressure changes and NA changes, and the profound changes in HR by nCPAP. Furthermore, it has to be mentioned that the blood pressure reductions in the hypertensive OSA group by far exceeded previously reported placebo effects in other studies. In the screening procedure, the assignment of the OSA patients to the normotensive or hypertensive group had been done using ambulatory blood pressure monitoring (ABPM). Mean daytime values of $135 \mathrm{mmHg}$ (systolic) and of $85 \mathrm{mmHg}$ (diastolic) correspond to the casual blood pressure limits of 140 and $90 \mathrm{mmHg}$ accepted as a cut-off for hypertension [24, 31]. Beyond this, studies have shown that end-organ damage correlates better with ABPM measurement than with office blood pressure [32]. Although this procedure was expected to better discriminate between the normo- and hypertensive state in the patients in the current study when compared with the conventional procedure of office blood pressure measurement, there was a considerable overlap in invasively assessed blood pressure during the baseline measurement between the two patient groups (fig. 3). However, the main results of the present study were not affected by this kind of study inclusion and part of the explanatory analysis was performed in the whole group accounting for blood pressure as a continuous variable.

The patients in the hypertensive group showed more severe OSA at baseline and were more obese when compared to normotensive subjects. Further analysis of the data using multiple regression analysis and partial correlation analysis revealed a statistical trend that the higher the RDI at baseline the greater the decrease in NApl with nCPAP therapy. However, such effects could not be demonstrated for blood pressure or HR. In this analysis, cardiovascular changes were not correlated to the BMI. This finding is in concordance with recent data suggesting that obesity in the absence of OSA is not accompanied by increased sympathetic activity [33]. Therefore, NApl are not likely to be affected by the extent of obesity.

In conclusion, the present data show that nasal continuous airway pressure substantially lowers sympathetic activity in hypertensive obstructive sleep apnoea patients, which occurred during both night- and daytime. This may be an important cause of the blood pressure reduction in these patients, although other well-known factors of blood pressure regulation have not been examined in this study. Interestingly, the change in heart rate with nasal continuous airway pressure may have a strong predictive value for the amount of blood pressure reduction. In normotensive obstructive sleep apnoea patients there is only a small decrease in both sympathetic activity and blood pressure. The fact that, in some previously published studies, blood pressure remained unchanged or showed only a small decrease with nasal continuous airway pressure may be due to the fact that most of the patients studied were normotensive. Therefore, studies evaluating the effect of nasal continuous airway pressure on blood pressure should focus on hypertensive obstructive sleep apnoea patients. The marked blood pressure reduction with nasal continuous airway pressure therapy seen in the obstructive sleep apnoea patients of this study may lead to a substantial reduction in cardiovascular risk in these patients.

\section{References}

1. Guilleminault C, Tilkian A, Dement WC. The sleep apnea syndromes. Ann Rev Med 1976; 27: 464484.

2. Young T, Palta M, Dempsey J, Skatrud J, Weber S, Badr S. The occurrence of sleep-disordered breathing among middleaged adults. N Engl J Med 1993; 328: 1230-1235.

3. Hla KM, Young TB, Bidwell T, Palta M, Skatrud JB, Dempsey J. Sleep apnea and hypertension. A populationbased study. Ann Intern Med 1994; 120: 382-388.

4. Ringler J, Basner RC, Shannon R, et al. Hypoxemia alone does not explain blood pressure elevations after obstructive apneas. J Appl Physiol 1990; 69: 2143-2148.

5. Smith ML, Niedermaier ON, Hardy SM, Decker MJ, Strohl KP. Role of hypoxemia in sleep apnea-induced sympathoexcitation. J Auton Nerv Syst 1996; 56: 184-190.

6. Eisenberg E, Zimlichman R, Lavie P. Plasma norepinephrine levels in patients with sleep apnea syndrome [letter]. $N$ Engl J Med 1990; 322: 932-933.

7. Marrone O, Riccobono L, Salvaggio A, Mirabella A, Bonanno A, Bonsignore MR. Catecholamines and blood pressure in obstructive sleep apnea syndrome. Chest 1993; 103: 722-727.

8. Hedner J, Ejnell H, Sellgren J, Hedner T, Wallin G. Is high and fluctuating muscle nerve sympathetic activity in the sleep apnoea syndrome of pathogenetic importance for the development of hypertension? J Hypertens 1988; 6: S529S531.

9. Narkiewicz K, Somers VK. The sympathetic nervous system and obstructive sleep apnea: implications for hypertension. J Hypertens 1997; 15: 1613-1619.

10. Wallin BG, Sundlof G, Eriksson BM, Dominiak P, Grobecker H, Lindblad LE. Plasma noradrenaline correlates to sympathetic muscle nerve activity in normotensive man. Acta Physiol Scand 1981; 111: 69-73.

11. Ehlenz K, Köhler U, Mayer J, Peter JH, von Wichert P, 
Kaffarnik H. Plasma levels of catecholamines and cardiovascular parameters during sleep in patients with sleep apnea. In: Peter JH, Podszus T, von Wichert P, eds. Sleep Related Disorders and Internal Diseases. Berlin, Springer, 1997; pp. 321-325.

12. Carlson JT, Hedner J, Elam M, Ejnell H, Sellgren J, Wallin BG. Augmented resting sympathetic activity in awake patients with obstructive sleep apnea. Chest 1993; 103: 1763-1768.

13. Grunstein RR. Sleep-related breathing disorders. Nasal continuous positive airway pressure treatment for obstructive sleep apnoea. Thorax 1995; 50: 1106-1113.

14. Sullivan CE, Issa FG, Berthon-Jones M, Eves L. Reversal of obstructive sleep apnoea by continuous positive airway pressure applied through the nares. Lancet 1981; 1: 862-865.

15. Engleman HM, Martin SE, Deary IJ. Effect of continuous positive airway pressure treatment on daytime function in sleep apnoea/hypopnoea syndrome. Lancet 1994; 343: 572-575.

16. Jennum P, Wildschiodtz G, Christensen NJ, Schwartz T. Blood pressure, catecholamines, and pancreatic polypeptide in obstructive sleep apnea with and without nasal continuous positive airway pressure (nCPAP) treatment. Am J Hypertens 1989; 2: 847-852.

17. Minemura $\mathrm{H}$, Akashiba $\mathrm{T}$, Yamamoto $\mathrm{H}$, Akahoshi $\mathrm{T}$, Kosaka N, Horie T. Acute effects of nasal continuous positive airway pressure on 24-hour blood pressure and catecholamines in patients with obstructive sleep apnea. Intern Med 1998; 37: 1009-1013.

18. Hedner J, Darpo B, Ejnell H, Carlson J, Caidahl K. Reduction in sympathetic activity after long-term CPAP treatment in sleep apnoea: cardiovascular implications. Eur Respir J 1995; 8: 222-229.

19. Pepperell JTC, Ramdassingh-Dow S, Crosthwaite N, et al. Ambulatory blood pressure after therapeutic and subtherapeutic nasal continuous positive airway pressure for obstructive sleep apnoea. Lancet 2002; 359: 204-210.

20. Faccenda JF, Mackay TW, Boon NA, Douglas NJ. Randomised placebo-controlled trial of continuous positive airway pressure on blood pressure in the sleep apneahypopnea syndrome. Am J Respir Crit Care Med 2001; 163 : 344-348.

21. Dimsdale JE, Loredo JS, Profant J. Effect of continuous positive airway pressure on blood pressure: a placebo trial. Hypertension 2000; 35: 144-147.

22. Engleman HM, Gough $\mathrm{K}$, Martin SE, Kingshott RN, Padfield PL, Douglas NJ. Ambulatory blood pressure on and off continuous positive airway pressure therapy for the sleep apnea/hypopnea syndrome: effects in "non-dippers". Sleep 1996; 19: 378-381.

23. Becker HF, Jerrentrup A, Ploch $\mathrm{T}$, et al. Effect of nasal continuous positive airway pressure treatment on blood pressure in patients with obstructive sleep apnea. Circulation 2003; 107: 68-73.

24. Baumgart P, Walger P, Jurgens U, Rahn KH. Reference data for ambulatory blood pressure monitoring: what results are equivalent to the established limits of office blood pressure? Klin Wochenschr 1990; 68: 723-727.

25. Rechtschaffen A, Kales A. A manual of standardized terminology: techniques and scoring system for sleep stages of human subjects. Los Angeles, UCLA Brain Information Service/Brain Research Institute, 1968.

26. Nelesen RA, Yu H, Ziegler MG, Mills PJ, Clausen JL, Dimsdale JE. Continuous positive airway pressure normalizes cardiac autonomic and hemodynamic responses to a laboratory stressor in apneic patients. Chest 2001; 119: 10921101.

27. Khoo MC, Kim TS, Berry RB. Spectral indices of cardiac autonomic function in obstructive sleep apnea. Sleep 1999; 22: $443-451$.

28. Suzuki M, Otsuka K, Guilleminault C. Long-term nasal continuous positive airway pressure administration can normalize hypertension in obstructive sleep apnea patients. Sleep 1993; 16: 545-549.

29. Ziegler MG, Mills PJ, Loredo JS, Ancoli-Israel S, Dimsdale JE. Effect of continuous airway pressure and placebo treatment on sympathetic nervous activity in patients with obstructive sleep apnea. Chest 2001; 120: 887-893.

30. Heude E, Bourgin P, Feigel P, Escourrou P. Ambulatory monitoring of blood pressure disturbs sleep and raises systolic pressure at night in patients suspected of suffering from sleep-disordered breathing. Clin Sci (Colch) 1996; 91: $45-50$.

31. The sixth report of the Joint National Committee on prevention, detection, evaluation, and treatment of high blood pressure. Arch Intern Med 1997; 157: 2413-2446.

32. Parati G, Pomidossi G, Albini F, Malaspina D, Mancia G. Relationships of $24 \mathrm{~h}$ blood pressure mean and variability to severity of target organ damage in hypertension. J Hypertension 1981; 5: 93-98.

33. Narkiewicz K, van de Borne PJ, Cooley RL, Dyken ME, Somers VK. Sympathetic activity in obese subjects with and without obstructive sleep apnea. Circulation 1998; 98: 772776 . 